\title{
ASSOCIATION OF TOOTH LOSS WITH TEMPOROMANDIBULAR DISORDERS
}

\section{Muhammad Umer Javed ${ }^{1-3 凶}$, Muhammad Adil Asim ${ }^{1,4}$, Fahimullah $^{3}$, Zarah Afreen ${ }^{1,5}$, Ammarah Afreen ${ }^{1,5}$, Amna Khalil ${ }^{1,6}$}

\begin{abstract}
OBJECTIVE: To determine the association of tooth loss with temporomandibular disorders (TMD) in in our local population.

METHODS: This case-control study was carried out in Department of Prosthodontics at Armed Forces Institute of Dentistry, Rawalpindi, Pakistan. A sample size of 285 subjects ( 95 cases and 190 controls) was enrolled in the study. Anamnestic questionnaire was administered to the patients fulfilling the criteria. Based on the score attained, patients were grouped as TMD patients (case) or TMD free patients (control). A pre-designed performa was used to record the data. SPSS v. 17.0 was used for descriptive and inferential analysis.
\end{abstract}

RESULTS: The mean age of the participants was $33.3 \pm 1 \mid .2$ years with male to female ratio of with I.26: I. Maximum of the participants (72\%) were of 4 I years or less. Overall mean number of missing teeth in all participants was $3.41 \pm 3.08$. Mean number of missing teeth in cases and controls was $4.46 \pm 3.65$ and $2.89 \pm 2.60$ respectively $(\mathrm{p}<0.00 \mathrm{I})$. Tooth loss of $<5$ teeth \& $\geq 5$ teeth was observed in 53 \& 42 cases as compared to 128 \& 62 controls respectively $(\mathrm{OR}=0.6 \mathrm{I} ; 95 \% \mathrm{Cl}: 0.36$ to I.0I; $\mathrm{p}$-vale 0.056$)$. The relationship for number of quadrants with number of missing teeth in cases and control groups was significant $(\mathrm{p}$-value $=<0.00 \mathrm{I})$.

CONCLUSION: Present study indicates that there is significant correlation between the numbers of quadrants with tooth loss and TMD. Increasing the number of quadrants with tooth loss will increase the risk of TMD. However, the number of teeth lost itself has no association with TMD.

KEY WORDS: Temporomandibular Disorders (MeSH); Temporomandibular Joint (MeSH); Tooth (MeSH); Tooth Loss (MeSH); Missing Teeth (Non-MeSH); Orofacial Pain (MeSH).

THIS ARTICLE MAY BE CITED AS: Javed MU, Asim MA, Fahimullah, Afreen Z, Afreen A, Khalil A. Association of tooth loss with temporomandibular disorders. Khyber Med Univ J 2020;12(I):29-33. DOI: I0.35845/kmuj.2020.19658.

\section{INTRODUCTION}

$\mathrm{P}$ ain involving the head and orofacial regions is very common affecting $26 \%$ and $12 \%$ respectively of the g e n e ral population. Temporomandibular disorders (TMD) is a term used to describe a number of related disorders involving the temporomandibular joints (TMJ), masticatory muscles, and occlusion and is one of the most common causes of orofacial pain.' In other words, it is a group of musculoskeletal conditions having some symptoms in common, such as pain, restricted movement, muscle tenderness and intermittent joint sounds. ${ }^{2}$

For more than 40 years, the etiology of TMJ pain has been a subject of debate. Modern etiologic theories for the development of TMD contains different external and internal factors. Currently, the multifactorial concept including predisposing (systemic, psychologic, anatomic, occlusal), initiating (micro-
I. Post Graduate Trainee, Armed Forces Institute of Dentistry (AFID), Rawalpindi, Pakistan.

2. Polyclinic Hospital, Islamabad, Pakistan.

3. Khyber Medical University Institute of Dental Sciences (KMU-IDS), Kohat, Pakistan

4. Rawal Institute of Health Sciences, Islamabad, Pakistan.

5. Watim Dental College, Rawalpindi, Pakistan.

6. Multan Medical and Dental College, Multan, Pakistan.

Email『: umerjaved86@gmail.com

Contact \#: +92-333-5364189

Date Submitted: $\quad$ August 31,2019

Date Revised: $\quad$ March 12,2020

Date Accepted: $\quad$ March 15,2020

and macrotrauma, parafunctional habits, over-loading) and perpetuating (mechanical and muscular stress, metabolic, behavioral, social and emotional) factors is accepted. ${ }^{3}$

An idiopathic concept of etiology at the level of the individual patient is also advocated. The effect of tooth loss on the etiology of TMDs is not reflected in evidence based data and thus, this has been an area of considerable debate in dentistry. A reduction of occlusal units has been associated with muscle and TMJ tenderness or pain $(10.5 \%$ of women and $9.5 \%$ of men). ${ }^{4}$

Decreased posterior occlusal support in patients with extremely shortened dental arches due to loss of both premolars and molars, may lead to risk of mandibular instability and TMDs (4.6\% in age $20-40$ years and $11.4 \%$ in age $>40$ years).

A higher prevalence of TMD was seen in individuals (especially young women) with fewer missing posterior teeth but in multiple quadrants. ${ }^{5}$ Higher incidence and intensity of TMD was found in subjects with greater tooth loss in the supporting zones $(46.9 \%)$ when comparing individuals with Eichner's class II and Eichner's class III. ${ }^{6}$ However, a high proportion (65-79\%) of patients with shortened dental arches were symptoms free.

The present study was therefore aimed to determine the relationship between tooth loss and the risk of development 
TABLE I: CASE WISE DISTRIBUTION OF MISSING TEETH

\begin{tabular}{|l|c|c|c|}
\hline \multirow{2}{*}{ Groups } & \multicolumn{2}{|c|}{ Number of Missing Teeth } & \multirow{2}{*}{ P-Value* } \\
\cline { 2 - 3 } & Mean & SD & \\
\hline TMD Patients (Cases) & 4.46 & 3.65 & \multirow{2}{*}{$<0.00$ I } \\
\hline TMD - Free Patients (Controls) & 2.89 & 2.60 & \\
\hline Total & 3.41 & 3.08 & \\
\hline
\end{tabular}

$T M D=$ Temporomandibular disorders; $S D=$ standard deviation *Independent samples $\mathrm{t}$-test

TABLE II: GROUP WISE ANALYSIS FOR THE DICHOTOMIZED CATEGORIES OF MISSING TEETH

\begin{tabular}{|l|c|c|c|c|}
\hline \multirow{2}{*}{ Risk Factor } & \multicolumn{2}{|c|}{ Tooth Loss } & $\begin{array}{c}\text { Odds Ratio } \\
(\mathbf{9 5 \%} \mathbf{C l})\end{array}$ & P-value \\
\cline { 2 - 5 } & Missing Teeth (<5) & Missing Teeth ( $\mathbf{2 5})$ & \\
\hline $\begin{array}{l}\text { TMD Patients } \\
(\text { Cases, } \mathrm{n}=95)\end{array}$ & 53 & 42 & $0.6 \mathrm{I}$ & 0.056 \\
\hline $\begin{array}{l}\text { TMD - Free Patients } \\
(\text { Controls, } \mathrm{n}=190)\end{array}$ & 128 & 62 & $(0.36-1.0 \mathrm{I})$ & \\
\hline
\end{tabular}

TABLE III: GROUP WISE COMPARISON OF THE NUMBER OF QUADRANTS WITH MISSING TEETH

\begin{tabular}{|c|c|c|c|c|c|c|}
\hline \multirow[b]{2}{*}{ Patient Status } & \multicolumn{5}{|c|}{ Number of Quadrants with Missing Teeth } & \multirow[b]{2}{*}{ P-Value* } \\
\hline & $\begin{array}{c}\text { No missing } \\
\text { tooth in } \\
\text { any } \\
\text { quadrant }\end{array}$ & $\begin{array}{c}\text { Teeth } \\
\text { missing in } \\
\text { one } \\
\text { quadrant }\end{array}$ & $\begin{array}{c}\text { Teeth } \\
\text { missing } \\
\text { in two } \\
\text { quadrants }\end{array}$ & $\begin{array}{c}\text { Teeth } \\
\text { missing } \\
\text { in three } \\
\text { quadrants }\end{array}$ & $\begin{array}{c}\text { Teeth } \\
\text { missing } \\
\text { in four } \\
\text { quadrants }\end{array}$ & \\
\hline $\begin{array}{l}\text { TMD Patients } \\
\text { (Cases, } n=95 \text { ) }\end{array}$ & 30 & 18 & 24 & 6 & 17 & \multirow{2}{*}{$<0.001$} \\
\hline $\begin{array}{l}\text { TMD - Free Patients } \\
\text { (Controls, } \mathrm{n}=190)\end{array}$ & 109 & 54 & 9 & 9 & 9 & \\
\hline
\end{tabular}

of TMDs in the local population. This would not only help in the appropriate diagnosis and management of patients with TMD but may also prove useful in identifying patients prone to TMD as a result of tooth loss due to dental disease or trauma. Immediate prosthodontic replacement of lost teeth in these high risk patients may also prove helpful the prevention of TMD.

\section{METHODS}

After approval from the Ethics Review Committee of Armed Forces Institute of Dentistry Rawalpindi (AFID), this case control study was conducted over a period of 2 years and 6 months (from 30.08.20I 0 to 28.02.20I3). Sample size was calculated using Epi Info Software version 6. I. Based on study by Dulcic6, 46.9\% TMD patients (exposure among cases) presented with some tooth loss. Whereas according to study by Witter, $65-79 \%$ of patients with shortened dental arches (lost posterior teeth) had no symptoms of TMD.7 Thus, exposure among controls was $65 \%$ with ratio of case to control as $1: 2$. The required sample size at $5 \%$ level of significance and $80 \%$ power was calculated as 95 cases and 190 controls.

Both male and female patients, with an age range of $18-60$ years, reporting to out-patient department of AFID were included in the study. Individuals with history of trauma, rheumatoid arthritis or developmental abnormality of the orofacial region, history of TMJ surgery or previous treatment for TMD were excluded from study. Informed consent was obtained, and assurance of confidentiality was provided. Anamnestic questionnaire was administered to the patients and based on the score attained, patients were grouped as TMD patient (case) or TMD free patient (control). The selfadministered anamnestic questionnaire, the Conti Anamnestic Questionnaire, comprising of ten questions regarding common TMD symptoms was used. ${ }^{8}$ This questionnaire, a modified version of Helkimo Index, has shown reliability in diagnosis of TMD. Patients having a score greater than three on the anamnestic questionnaire were grouped as cases while patients having score less than or equal to three were categorized in controls group. Age, gender, number of lost teeth, number of quadrants with lost teeth and Eicher's index were also recorded in data collection proforma. Third molars were not considered in calculations of the number of lost teeth.

Data was analyzed using SPSS version 17. For continuous variables like age and number of lost teeth, mean and standard deviation were calculated. For categorical variables like gender, Eichner's index, proportions as percentages were reported. The data for the number of missing teeth was dichotomized into two groups: one with less than five teeth lost and the other with more than five teeth lost. To detect any difference in the number of lost teeth with the dichotomized groups as applied to the case and control groups and the Pearson's chi square test and odds ratio (confidence interval $95 \%$ ) test was applied. To analyze any difference between the numbers of quadrants with lost teeth between the two groups, chi square test was applied. Two samples $t$ test was used to analyze the difference in number of missing teeth between two groups. $P$ value of $\leq 0.05$ was considered significant.

\section{RESULTS}

Out of 285 participants, 159 (55.8\%) were males and 126 (44.2\%) were females with I.26:I male to female ratio. The mean age of the participants was $33.3+11.2$ years. About $72 \%(n=$ 204) of the participants were of $4 I$ years of age or less. Only $9.5 \%(n=28)$ of the participants were of 50 years of age or older.

In this study 95 patients (33.3\%) were included in case group while control group had 190 patients $(66.7 \%)$. The total number of lost teeth was reported for all participants.

Overall mean number of missing teeth 
in all participants was $3.4 I \pm 3.08$. Mean number of missing teeth in cases and controls is given in (Table $\mathrm{I}$ ).

The variable 'tooth loss' was dichotomized into two groups: less than five missing teeth; and five or more missing teeth. Chi-squared test was applied to test the relationship of frequency distribution among cases and control groups for 'tooth loss' (Table II). Tooth loss of $<5$ teeth \& $\geq 5$ teeth was observed in 53 \& 42 cases as compared to $128 \& 62$ controls respectively $(\mathrm{OR}=0.6 \mathrm{I})$.

The data were further analyzed to assess the frequency distribution of quadrants with missing teeth between the two groups. The number of quadrants with lost teeth had four subgroups (no quadrant, one quadrant, two quadrants, three quadrants and four quadrants), as illustrated in Table III. Chi-squared test was applied which showed a significant relationship $(p<$ $0.00 \mathrm{I}$ ) for number of quadrants with lost teeth. The relationship for number of quadrants with number of missing teeth in cases and control groups was significant $(p$-value $=<0.00 \mathrm{I})$.

\section{DISCUSSION}

The role of tooth loss as a risk marker for TMDs has been a source of conflict in the literature. Multiple hypotheses have been proposed to explain the biologic mechanisms in this regard. It has been hypothesized that the lack of molar support led to a flawed condylar position causing upward and backward movement of the condyles resulting in adverse loading of the joint apparatus.

Hylander proposed the 'lever-action model' whereby, left/ right asymmetric loss of teeth results in asymmetric stresses being transferred to the temporomandibular joint which eventually leads to degenerative changes in the temporomandibular joint. 10,11

Occlusion is frequently cited as one of the major etiological factors causing TMDs and it is well known that tooth loss can result in development of malocclusion and occlusal interferences due to overeruption and mesial movement of opposing and nearby teeth. Although the degree of occlusal disharmony has not proven to be a good indicator of severity of the TMD, unstable occlusion can be regarded as a predisposing factor. These studies have documented the role of occlusion as a predisposing, initiating and/ or perpetuating factor in the etiology of TMD. ${ }^{12,13}$

Results of the present study indicate that a significantly greater tooth loss was found among patients with TMDs, in comparison to the control group. However, an OR of 0.61 with $95 \% \mathrm{Cl}$ suggesting a statistically insignificant range (0.36-1.0I) shows a weaker association of number of teeth lost and TMD. Pullinger and Seligman ${ }^{14}$ found that occlusal factors have a role in about $10-20 \%$ to the total of causative factors of TMD. They affirm that occlusal factors may be considered co-factors when diagnosing patients with TMD, but its value should not be superestimated. Rather than a causal role, an occlusal discrepancy seems to be TMD consequency. They reported a low correlation between occlusion and TMD which is accordance with the results of our study. Results of our study are also hand in hand with results of another recent study of the kind in Indonesia. ${ }^{15}$ In another recent study in India, statistically insignificant difference was seen between posterior tooth loss group of patients and patients have posterior teeth replaced with removable dentures in their association with signs and symptoms of TMD. This indicates no association between tooth loss and signs and symptoms of TMD. ${ }^{16}$

Luder, et al. evaluated the influence of tooth loss on temporomandibular joint degeneration in 53 autopsy specimens ranging in age from 15 to 92 years. The study concluded that reduction in the length of dental arch was a significant factor in temporomandibular joint degeneration. ${ }^{17}$ Similar findings were also observed by Whittaker, et al. who conducted a study on a large collection of Romano-British skulls. The Whittaker study reported that changes in the form or shape of the condyles is possibly correlated to the number of teeth lost. ${ }^{18}$ Christensen, et al. ${ }^{19}$ in their study on animal models and Tallent, et al. ${ }^{20}$ in a recent study reported a positive relation between missing mandibular posterior teeth and development of TMDs.

However, other studies provide conflicting evidence regarding the role of missing teeth and TMD. Kanno, et al. ${ }^{21}$ reviewed the literature on shortened dental arches and found that although a decrease of molar support did bring about certain morphological changes in the temporomandibular joint, these changes were largely adaptive rather than pathologic. No significant difference in the signs and symptoms of TMD between the groups with shortened and complete dental arches was observed.

Holmlund $A$, et al. studied the prevalence of TMJ, osteoarthrosis and synovitis in 60 patients with painful chronic locking of the TMJ by clinical examination, tomography and of the joint. The study revealed no statistical differences between fully dentate subjects and those with reduced molar occlusion in any form of assessment. The author further stated that the results do not support prosthetic replacement of lost molars as a preventive measure for temporomandibular joint osteoarthrosis. ${ }^{22}$

In a study conducted by Sarita, et al. on 850 Tanzanian subjects, no evidence was found that temporomandibular disorder was associated with shortened dental arches. However, when all posterior teeth were unilaterally or bilaterally absent, the risk for joint symptoms increased. ${ }^{23}$

The findings of the present study are in agreement with the findings of the study conducted by Wang et al. ${ }^{5}$ which revealed some interesting findings in this perspective. The purpose of the study was to investigate the influence of number of lost posterior teeth and number of dental quadrants with lost posterior teeth with a logistic regression model in context of the disagreement found in the literature about the association between missing posterior teeth and the presence of TMD. A total of 74I individuals, aged 21-60 years, with missing posterior teeth were included out of which 386 suffered from TMD and 355 were free 
from temporomandibular disorders. The results showed that the impact of the number of missing posterior teeth was insignificant but when analyzed together with the variable of the number of dental quadrants with missing posterior teeth, the number of missing posterior teeth was found to have a significant effect on the incidence of temporomandibular disorders. This implied that when individuals who had lost posterior teeth, lost additional posterior teeth adjacent to the primarily lost one's, the risk of having temporomandibular disorders is likely be lower than it would be for those whose who lost additional posterior teeth located in a different dental quadrant. Conversely, individuals with fewer missing posterior teeth but in more quadrants, have a higher prevalence of temporomandibular disorders.

The present study provides evidence that an increase in number of quadrants with missing teeth is associated with an increased risk of TMD while the number of teeth lost has a weaker association with TM. A randomized control trial which explores the impact of replacing missing teeth in TMD patients would help in establishing the association between tooth loss and the development of TMD. However, such a study that entails replacing missing teeth prosthetically for merely treating temporomandibular disorders, an indication not backed by concrete scientific evidence, may carry serious ethical and legal implications.

\section{CONCLUSION}

The results of the present study indicate that there is significant correlation between the numbers of quadrants with tooth loss and TMD. Increasing the number of quadrants with tooth loss will increase the risk of TMD. However, the number of teeth lost itself has no association with TMD.

\section{REFERENCES}

I. Balasubramaniam R, Delcanhol R. Temporomandibular disorders and related headache. In: Selvaratnam P, Niere KR, Zuluaga MI, Oddy P (eds). Headache, Orofacial Pain and
Bruxism - Diagnosis and multidisciplinary approaches to management. 2009;pp69-82. Churchill Livingstone, Elsevier, UK.

2. Bonjardim LR, Lopes-Filho RJ, Amado G, Albuquerque RL, Goncalves SR. Association between symptoms of temporomandibular disorders and gender, morphological occlusion, and psychological factors in a group of university students. Indian J Dent Res 2009;20(2):190-4. DOI: 10. 4103/0970-9290.5290I.

3. Oral K, Bal Küçük B, Ebeoğlu B, Dinçer S. Etiology of temporomandibular disorder pain. Agri 2009;2I (3):89-94.

4. Mundt T, Mack F, Schwahn C, Bernhardt O, Kocher T, John U, et al. Gender Differences in Associations between Occlusal Support and Signs of Temporomandibular disorders: Results of the Population-Based Study of Health in Pomerania (SHIP). Int J Prosthodont 2005; I8(3):232-9.

5. Wang MQ, Xue F, He JJ, Chen JH, Chen CS, Raustia A. Missing posterior teeth and risk of temporomandibular disorders. J Dent Res 2009;88(I0):942-5. DOI: I0. I I77/0022034509344387.

6. Dulcic N, Panduric J, Kraljevic S, Badel T, Celic R. Incidence of Temporomandibular Disorders at Tooth Loss in the Supporting Zones. Coll Antropol 2003;27(Suppl 2):6I-6.

7. Witter DJ, Kreulen CM, Mulder J, Creugers NH. Signs and symptoms related to temporomandibular disorders--Follow-up of subjects with shortened and complete dental arches. J Dent 2007;35(6):521-7. DOI: 10.1016/j.jdent.2007.02.003.

8. Conti PC, Ferreira PM, Pegoraro LF, Conti JV, Salvador MC. A crosssectional study of prevalence and etiology of signs and symptoms of temporomandibular disorders in high school and university students. J Orofac Pain 1996; 10(3):254-62.

9. Molin C. From bite to mind: TMD-- a personal and literature review. Int J Prosthodont 1999; 12(3):279-88.

10. Hylander WL. The human mandible: lever or link? Am J Phys Anthropol 1975;43(2):227-42. DOI: 10.1002/ ajpa. 1330430209.

II. Sheridan SG, Mittler DM, Van Gerven DP, Covert HH. Biomechanical association of dental and temporomandibular pathology in a medieval Nubian population. Am J Phys Anthropol 199|;85(2): 201-5. DOI: 10.1002/ajpa. 1330850208.

12. Khan MF, Gull S, Chatha MR. Temporomandibular Disorders. Pak Oral Dental J Dec 20 I I;3 I(2):26672.

13. Cooper BC; International College of Cranio-Mandibular Orthopedics (ICCMO). Temporomandibular disorders: A position paper of the International College of CranioMandibular Orthopedics (ICCMO). Cranio 20II;29(3):237-44. DOI: 10.1179/crn.2011.034.

14. Pullinger AG, Seligman DA. Quantification and validation of predictive values of occlusal variables in temporomandibular disorders using a multifactorial analysis. J Prosth Dent 2000;83(I): 66-75. DOI: $10.1016 / \mathrm{s} 0022-3913$ (00)70090-4.

15. Chairunnisa R, Sihombing RJ. The Association between Number of Tooth Loss, Tooth Loss Quadrants, and Occlusal Support with Temporomandibular Disorders in Partially Edentulous Patients. Adv Health Sci Res 2017;8:255-8. DOI: 10.299|/idcsu- | 7.20|8.65.

16. Manchikalapudi G, Polasani LR. Correlation between posterior edentulousness and temporomandibular disorder in adult population: A case control study. Int Arch Integr Med 2017;4(I0): I43-50.

17. Luder HU. Factors affecting degeneration in human temporomandibular joints as assessed histologically. Eur J Oral Sci 2002; I I0(2): 106-I3. DOI: 10.1034/ j. I600-0722.2002.I I 2 I 2.x. 
18. Whittaker DK, Davies G, Brown M. Tooth loss, attrition and temporomandibular joint changes in a Romano-British population. J Oral Rehabil 1985;12(5):407-19. DOI: | 0. I । I I/j. I 365-2842. I 985. tb0I546.x.

19. Christensen LV, Ziebert GJ. Effects of experimental loss of teeth on the temporomandibular joint. J Oral Rehabil 1986;13(6):587-98. DOI: | 0. I I I I/j. I 365-2842. I 986.tb 00682.x.

20. Tallents RH, Macher DJ, Kyrkanides
S, Katzberg RW, Moss ME. Prevalence of missing posterior teeth and intraarticular temporomandibular disorders. J Prosthet Dent 2002;87(I):45-50. DOI: 10.1067/mpr.2002.121487.

21. Kanno T, Carlsson GE. A review of the shortened dental arch concept focusing on the work by the Käyser/Nijmegen group. J Oral Rehabil 2006;33(II):850-62. DOI: I 0. I I I I/j. I365-2842.2006. 01625.x.

22. Holmlund A, Axelsson S.
Temporomandibular joint osteoarthrosis. Correlation of clinical and arthroscopic findings with degree of molar support. Acta Odontol Scand 1994;52(4):214-8. DOI: $10.3109 / 000163594090$ 29049.

23. Sarita PT, Kreulen CM, Witter D, Creugers NH. Signs and symptoms associated with TMD in adults with shortened dental arches. Int J Prosthodont 2003; I6(3):265-70.

\section{AUTHORS' CONTRIBUTIONS}

Following authors have made substantial contributions to the manuscript as under:

MUJ: Conception \& study design, acquisition of data, drafting the manuscript, final approval of version to be published.

MAA: Analysis and interpretation of data, critical revision, final approval of version to be published.

Fa: Conception \& study design, critical review, final approval of version to be published.

ZA, AA \& AK: Acquisition of data, critical review, final approval of version to be published.

Authors agree to be accountable for all aspects of the work in ensuring that questions related to the accuracy or integrity of any part of the work are appropriately investigated and resolved.

CONFLICT OF INTEREST
Authors declared no conflict of interest
GRANT SUPPORT AND FINANCIAL DISCLOSURE
NIL

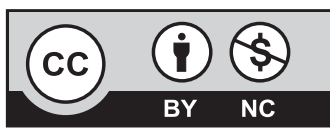

This is an Open Access article distributed under the terms of the Creative Commons Attribution-Non Commercial 2.0 Generic License.

KMUJ web address: www.kmuj.kmu.edu.pk Email address: kmuj@kmu.edu.pk 